\title{
Covid-19 infection in pregnant women in Dubai: a case-control study
}

Komal Sundeep Hazari', Rasha Abdeldayem¹, Litty Paulose1 , Nimmi Kurien², Zukaa Almahloul', Hozaifah Mohammad ${ }^{2}$, Taghrid Faek A. Elgergawi ${ }^{1}$, Maryam Alkhanbouli ${ }^{1}$, Khalid Mahmoud ${ }^{1}$, Atif Bashir Fazari ${ }^{1}$, Amar Hassan ${ }^{3}$ and Riad Bayoumi ${ }^{3,4^{*}}$

\begin{abstract}
Background: Whilst the impact of Covid-19 infection in pregnant women has been examined, there is a scarcity of data on pregnant women in the Middle East. Thus, the aim of this study was to examine the impact of Covid-19 infection on pregnant women in the United Arab Emirates population.

Methods: A case-control study was carried out to compare the clinical course and outcome of pregnancy in 79 pregnant women with Covid-19 and 85 non-pregnant women with Covid-19 admitted to Latifa Hospital in Dubai between March and June 2020.

Results: Although Pregnant women presented with fewer symptoms such as fever, cough, sore throat, and shortness of breath compared to non-pregnant women; yet they ran a much more severe course of illness. On admission, $12 / 79(15.2 \%)$ Vs $2 / 85(2.4 \%)$ had a chest radiograph score [on a scale $1-6]$ of $\geq 3$ ( $p$-value $=0.0039$ ). On discharge, $6 / 79(7.6 \%)$ Vs $1 / 85$ (1.2\%) had a score $\geq 3$ ( $p$-value $=0.0438$ ). They also had much higher levels of laboratory indicators of severity with values above reference ranges for C-Reactive Protein [(28 (38.3\%) Vs 13 (17.6\%)] with $p<0.004$; and for D-dimer [32 (50.8\%) Vs 3(6\%)]; with $p<0.001$. They required more ICU admissions: 10/79 (12.6\%) Vs 1/85 (1.2\%) with $p=0.0036$; and suffered more complications: $9 / 79$ (11.4\%) Vs 1/85 (1.2\%) with $p=0.0066$; of Covid-19 infection, particularly in late pregnancy.

Conclusions: Pregnant women presented with fewer Covid-19 symptoms but ran a much more severe course of illness compared to non-pregnant women with the disease. They had worse chest radiograph scores and much higher levels of laboratory indicators of disease severity. They had more ICU admissions and suffered more complications of Covid-19 infection, such as risk for miscarriage and preterm deliveries. Pregnancy with Covid-19 infection, could, therefore, be categorised as high-risk pregnancy and requires management by an obstetric and medical multidisciplinary team.
\end{abstract}

Keywords: Covid-19, High-risk pregnancy, Neonate, Pneumonia, Neonatal morbidity, Maternal morbidity, Dubai

*Correspondence: Riad.bayoumi@mbru.ac.ae

${ }^{4}$ College of Medicine, Mohammed Bin Rashid University of Medicine

and Health Sciences, Dubai, United Arab Emirates

Full list of author information is available at the end of the article

\section{Background}

Coronavirus disease 2019 (Covid-19) is caused by the novel severe acute respiratory syndrome coronavirus 2 (SARS-CoV-2). In March 2020, the Covid-19 outbreak was declared a pandemic by the World Health Organization [1, 2]. By January 2021, more than 90 million confirmed cases had been reported globally, with a mortality rate of $2.2 \%$. In the United Arab Emirates, a 
total of 233,000 cases were reported, with 710 deaths [3]. Currently, there is appreciable data available on Covid-19 infection in pregnant women in the literature worldwide. However, there is little published data on the pattern of Covid-19 infection in pregnant women and the maternal/foetal outcomes from the Middle East in general, and the United Arab Emirates in particular [4].

The maternal immune system faces challenges in establishing and maintaining tolerance to the foetus and simultaneously defending against microbial challenges. Physiological changes that occur in the respiratory and circulatory systems during pregnancy, such as an elevated diaphragm, enhanced oxygen consumption and oedema of the mucosa of the respiratory tract, reduce tolerance to hypoxia and can worsen clinical outcomes when infected with a virus. This makes the women more vulnerable to severe symptoms from viral infections, as seen in studies of the common flu, severe acute respiratory syndrome (SARS) and Middle East respiratory syndrome [5-8].

Although the mortality in the overall population was $\geq 2.6 \%$ in the 1918 influenza pandemic, it was as high as $37 \%$ among pregnant women $[9,10]$. An increased risk of complications in pregnant women was also reported during the 2009 H1N1 influenza pandemic, and pregnant women were more than four times more likely to be admitted to hospital than were the general population [6]. Wong and colleagues [5] reported that $50 \%$ of pregnant women who developed SARS were admitted to an intensive care unit (ICU); around 33\% required mechanical ventilation and the mortality rate was as high as $25 \%$.

To date, the two largest studies on Covid-19 in pregnancy were carried out by the Oxford University National Perinatal Epidemiology Unit in the UK Obstetric Surveillance System [11, 12] and the US CDC National Notifiable Diseases Surveillance System [13, 14]. 'These two studies reported the impact of Covid-19 infection in 427 pregnant women in the UK and 23,434 women in the US. Interim reports from both studies confirmed the generally mild clinical course of SARS-CoV-2 infection during pregnancy.

In the UK series, most women came from black or minority ethnic groups. They presented with mild symptoms in early pregnancy but had moderate-to-severe illness in late pregnancy. Despite this, most women had good outcomes. The disease severity in pregnant women who were hospitalised was comparable to that of the general population, with a mortality rate of $1.0 \%$ [12]. Transmission of SARS-CoV-2 to infants was uncommon. In the US, pregnant women with Covid-19 infection were more likely to be admitted to hospital and receive respiratory support than non-pregnant women, as was found in the UK-based report [14].
Data on the clinical manifestations, risk factors and maternal and perinatal outcomes of Covid-19 in pregnancy have recently been compiled in a systematic review and meta-analysis of 77 studies with over 11,432 patients by Allotey et al. [15]. The results were essentially similar to the two major studies from the UK and US.

In this study, we aimed to examine the impact of Covid19 infection on pregnant women in the United Arab Emirates population and examine the clinical picture of this disease against the worldwide view. To this aim, we carried out a case-control study to compare the clinical course between pregnant and non-pregnant women with Covid-19, as well as to assess the outcome of pregnancy in pregnant women, in Dubai. The patients were admitted to Latifa Women and Children Hospital in Dubai between March and June 2020.

\section{Patients and methods}

\section{Study design and population}

The study was conducted in Latifa Women and Children Hospital, which is a 440-bed public tertiary care centre in Dubai that specialises in maternal, neonatal and paediatrics services. During the Covid-19 pandemic, most of the hospitals' wards were converted into isolation units for infectious diseases to accommodate patients with Covid-19.

From March 21st to June 30th, 2020, 444 patients (242 males and 202 females) were admitted to Latifa Hospital with Covid-19 infection. A Questionnaire was administered to establish if they had contact with someone positive for Covid-19. Of these, all pregnant women positive for Covid-19 were enrolled in the study. They were admitted for medical or obstetric reasons or had confirmed contact with a person infected with Covid-19. All patients were tested by Reverse Transcription-Polymerase Chain Reaction (RT-PCR) using nasopharyngeal swab for respiratory tract infection by SARS-CoV-2.

Seventy-nine pregnant women with confirmed SARSCOV-2 infection were identified and included in the case arm of the study. Their mean gestational age at presentation was 26 weeks; 17 (22\%) were in their first trimester, $15(19 \%)$ were in their second trimester, and the remaining 47 (59\%) were in their third trimester. A total of 85 non-pregnant women positive for Covid-19, admitted during the same period, were included in the control arm of the study. A special effort was made to best match the cases and controls in terms of demographic features and the presence of co-morbidities, such as a prior diagnosis of cardiac disease, hypertension, diabetes or respiratory disease, and any medication used.

Within the case and control arms, we further categorised patients as asymptomatic, mild, moderate, severe or critical according to the National Institutes of Health 
categorization of Covid-19 severity [16], which is as follows:

i. Asymptomatic: Patients have no symptoms but are positive for SARS-CoV-2.

ii. Mild: Patients have symptoms and signs of Covid19 , such as fever, cough, sore throat, malaise, headache, or muscle pain, but no shortness of breath, dyspnoea, or abnormal chest X-ray findings.

iii. Moderate: Patients have clinical or imaging findings suggestive of lower respiratory disease but have maintained an oxygen saturation above 93\% on room air.

iv. Severe: Patients' respiratory rate is above $30 / \mathrm{min}$, oxygen saturation is below or equal to $93 \%, \mathrm{PaO} 2 /$ $\mathrm{FiO} 2<300$ and/or pneumonic infiltrates involving more than $50 \%$ of the lung are seen.

v. Critical: Patients suffer respiratory failure, septic shock and/or multiple organ dysfunction, probably due to cytokine storm $[17,18]$.

\section{Data collection}

Data were collected from both study arms (pregnant and non-pregnant) from the Dubai Health Authority's unified electronic medical records system, which is called "Salama". The information collected was categorised and included demographic data, medical and obstetric history, physical examination results, laboratory investigation results, chest radiographs, treatment protocols, and maternal and neonatal outcomes. The standardised collected data were entered into an SPSS data collecting sheet designed specifically for this study.

\section{Chest X-ray scoring}

To determine the severity of pneumonia, a chest radiograph severity scoring system was adopted [19]. Each lung was divided into upper, middle, and lower zones, resulting in a total of 6 zones per patient. A zone was given a binary score depending on the presence or absence of opacities. The images were also classified as exhibiting ground glass opacities, reticular patterns, or consolidations, according to a recent report from Toussie et al. [19].

The lower lung zone extends from the costophrenic sulcus to the inferior hilar markings; the middle zone from the inferior hilar markings to the superior hilar markings; and the upper zone from the superior hilar markings to the apices.

\section{Treatment protocol}

COVID-19 positive patients were treated according to the UAE National Guidelines for Clinical Management and Treatment of COVID-19 [20] and following the $\mathrm{NIH}$ guidelines [16]. Based on the clinical severity and after thorough assessment of the patient, the COVID19 patients were treated with appropriate antimalarials (Chloroquine Phosphate/Hydroxychloroquine Sulfate), antivirals (Favipiravir in non-pregnant women), antiretrovirals (Lopinavir / Ritonavir), steroids, antibiotics, immunosuppressants (Tocilizumab), Interferon and prophylactic or therapeutic anti-coagulants (Table 1).

Table 1 The drugs and treatment regimens used in treatment of women with Covid-19 infection

\begin{tabular}{|c|c|c|}
\hline Generic name & Dose & Duration \\
\hline Hydroxychloroquine & Two loading doses of $400 \mathrm{mg}$ followed by $200 \mathrm{mg}$ twice daily & 7-14 days \\
\hline Chloroquine base & 300 mg (base) twice daily & 5-7 days \\
\hline Lopinavir-Ritonavir (200mg/50mg) & 400mg/100mg twice daily & 5-7 days (maximum 14 days) \\
\hline Favipiravir & $\begin{array}{l}\text { Two loading doses of } 1600 \mathrm{mg} \text { over } 1 \text { day followed by } 600 \mathrm{mg} \text { twice } \\
\text { daily }\end{array}$ & 5-7 days \\
\hline Tocilizumab & $\begin{array}{l}\text { 4-8 } \mathrm{mg} / \mathrm{kg} \text { ( } \max 400 \mathrm{mg} \text { ) followed by a second dose after 8-12 hours, } \\
\text { and then a third dose 8-12 hours later }\end{array}$ & 3 doses within 24 hours \\
\hline Pegylated interferon & 180 mcg, maximum of 2 doses 1 week apart & 2 doses within one week \\
\hline $\begin{array}{l}\text { Low Molecular Weight Heparin (LMWH) } \\
\text { [Prophylactic] }\end{array}$ & $\begin{array}{l}\text { According to Body weight: } 50-90 \mathrm{~kg}: 40 \mathrm{mg} \text { once daily. } 91-130 \mathrm{~kg}: 60 \mathrm{mg} \\
\text { once daily. } \\
\text { 131-170kg: } 80 \mathrm{mg} \text { once daily. }\end{array}$ & Till clinical improvement \\
\hline $\begin{array}{l}\text { Low Molecular Weight Heparin (LMWH)- } \\
\text { Therapeutic in critical Covid-19 pneumonia } \\
\text { patients }\end{array}$ & $\begin{array}{l}\text { 50-90kg: } 40 \mathrm{mg} \text { twice daily } \\
\text { 91-130kg: } 60 \mathrm{mg} \text { twice daily } \\
\text { 131-170kg: } 80 \mathrm{mg} \text { twice daily }\end{array}$ & Till clinical improvement \\
\hline Methylprednisolone & $0.5-1 \mathrm{mg} / \mathrm{kg}$ in 2 divided doses & $\begin{array}{l}3 \text { days in Non-ICU \& 5-7 days } \\
\text { in ICU patients. }\end{array}$ \\
\hline $\mathrm{N}$-acetyl cysteine & Two 1200 mg doses followed by 600 mg thrice daily & 7-14 days \\
\hline
\end{tabular}


Patients were considered cured after two consecutive negative (RT-PCR) nasopharyngeal swabs.

\section{Statistical analysis}

Data were analysed using IBM-SPSS for Windows version 25.0 (SPSS Inc., Chicago, IL). Categorical variables are described by using proportions. Continuous variables are described by a measure of tendency and a measure of dispersion. Continuous data was tested for normality by using Kolmogorov-Smirnov test. The Mann-Whitney test and $\mathrm{t}$-test were used when appropriate to compare means between continuous variable. Categorical variables were cross-tabulated to examine the independence between variables; for these variables, the $x^{2}$-square test or Fisher's exact test were used as appropriate. A $P$-value of less than 0.05 was considered significant for all analyses.

\section{Results}

\section{Demographic characteristics and comorbidities}

Demographic characteristics and comorbidities of pregnant and non-pregnant women with confirmed SARS-CoV-2 infection are shown in Table 2. There was a significant difference in mean age between the

Table 2 Demographic characteristics and comorbidities of pregnant and non-pregnant women with confirmed SARS-CoV-2 infection

\begin{tabular}{|c|c|c|c|}
\hline & $\begin{array}{l}\text { Pregnant } \\
(n=79) \\
{[n(\%)]}\end{array}$ & $\begin{array}{l}\text { Non-pregnant } \\
(n=85) \\
{[n(\%)]}\end{array}$ & $P$-value \\
\hline \multicolumn{4}{|l|}{ Age (years) ${ }^{a}$} \\
\hline$<=29$ & $23(29)$ & $21(25)$ & \\
\hline $30-40$ & $51(65)$ & $46(54)$ & 0.024 \\
\hline$>=41$ & $5(6)$ & $18(21)$ & \\
\hline \multicolumn{4}{|l|}{$\mathrm{BMI}\left(\mathrm{kg} / \mathrm{m}^{2}\right)^{\mathrm{a}}$} \\
\hline Normal & $39(49)$ & $57(68)$ & \\
\hline Overweight & $37(47)$ & $25(30)$ & 0.056 \\
\hline Obese & $3(4)$ & $2(2)$ & \\
\hline \multicolumn{4}{|l|}{ Nationality [n (\%)] $]^{\mathrm{a}}$} \\
\hline UAE & $37(47)$ & $27(32)$ & \\
\hline Other Nationalities & $42(53)$ & $58(68)$ & 0.814 \\
\hline \multicolumn{4}{|l|}{ Co-morbidities $[\mathrm{n}(\%)]^{\mathrm{b}}$} \\
\hline None & $48(61)$ & $58(68)$ & 0.3503 \\
\hline Asthma & $4(5)$ & $4(5)$ & 1.000 \\
\hline Chronic Lung Disease & $3(4)$ & $5(6)$ & 0.5596 \\
\hline Diabetes Mellitus & $14(17)$ & $4(5)$ & 0.0136 \\
\hline Gestational Diabetes & $3(4)$ & 0 & 0.0634 \\
\hline Hypertension & $3(4)$ & $7(8)$ & 0.2853 \\
\hline Hypothyroidism & $3(4)$ & $6(7)$ & 0.4034 \\
\hline Other disease & $5(6)$ & $1(1)$ & 0.0788 \\
\hline
\end{tabular}

\footnotetext{
${ }^{a}$ X2-square test was used for age, weight, and nationality
}

${ }^{b}$ Mann-Whitney test was used for co-morbidities
Covid-19-positive pregnant women $(32.7 \pm 5.5$ years $)$ and Covid-19 positive non-pregnant women (34.9 \pm 6.9 years); with $p$-value of 0.024 . There was also a significant difference in mean BMI between pregnant women (29.4 $\left.\pm 5.5 \mathrm{~kg} / \mathrm{m}^{2}\right)$ and non-pregnant women $(27.6 \pm 5.2 \mathrm{~kg} /$ $\mathrm{m}^{2}$ ); with a $p$-value of 0.033

A total of $39 \%$ of the pregnant women suffered from comorbidities, as compared to $32 \%$ of non-pregnant women. Diabetes mellitus was the most common comorbidity in the pregnant women $(17 \%)$ but was only $5 \%$ in the non-pregnant women.

\section{Symptoms}

Fever was the most common presenting symptom in both groups, followed by myalgia, sore throat, cough, and shortness of breath. Headache and runny nose were more commonly observed in the pregnant group (Table 3). The frequency of presenting symptoms in pregnant women of fever, cough, sore throat, and shortness of breath, is lower than that observed in non-pregnant women. This could be related to lower rates of direct contact, established by questionnaire, of pregnant women with individuals positive for Covid-19 (27; 34\%) compared to contact of nonpregnant women with individuals positive for Covid-19 (50; 59\%). However, the severity of symptoms was higher among pregnant women; and worsened as pregnancy advanced.

\section{Chest radiograph scores}

On admission, 12/79 (15.2\%) pregnant women and only 2/85 (2.4\%) non-pregnant woman had a chest radiograph score $\geq 3$; $(p$-value $=0.0039)$. During their hospital stay, 11/79 (13.9\%) pregnant women and 9/85 (10.6\%) non-pregnant women had a score of $\geq 3$ ( $p$-value is $=$ 0.5199). On discharge, 6/79 (7.6\%) pregnant women had

Table 3 Presenting symptoms in pregnant and non-pregnant women with confirmed SARS-CoV-2 infection

\begin{tabular}{llll}
\hline & $\begin{array}{l}\text { Pregnant } \\
(\boldsymbol{n}=\mathbf{7 9}) \\
\mathbf{N}(\%)\end{array}$ & $\begin{array}{l}\text { Non-pregnant } \\
(\boldsymbol{n}=\mathbf{8 5})\end{array}$ & $\boldsymbol{P}$-value \\
$\mathbf{N}(\%)$ & \\
\hline Fever & $18(23)$ & $47(55)$ & 0.005 \\
Cough & $6(8)$ & $17(20)$ & 0.02 \\
Sore throat & $8(10)$ & $19(22)$ & 0.028 \\
Shortness of breath & $6(8)$ & $17(20)$ & 0.02 \\
Headache & $10(13)$ & $12(20)$ & 0.145 \\
Running nose & $10(13)$ & $6(7)$ & 0.173 \\
Loss of smell/taste & $4(5)$ & $4(5)$ & 0.599 \\
Loose stools & $3(4)$ & $6(7)$ & 0.268 \\
Myalgia & $9(11)$ & $24(28)$ & 0.006 \\
\hline
\end{tabular}

Data were acquired at Latifa Hospital, Dubai, from March to June 2020 
a score $\geq 3$ compared to only $1 / 85$ (1.2\%) non-pregnant woman $(p$-value $=0.0438)$. In general, pregnant women presented with worse radiograph findings on admission and throughout their course of illness than non-pregnant women (Fig. 1).

On admission and throughout the hospital stay, two laboratory indicators of severity of Covid-19 infection; C-Reactive Protein (C-RP) and D-dimer were significantly higher in pregnant women than in non-pregnant women (Table 4). Values above reference ranges for C-RP were $[(28(38.3 \%)$ vs13 $(17.6 \%)]$ with $p<0.004$ and for D-dimer [32 (50.8\%) vs 3(6\%)]; $p<0.001$. However, differences in lactate dehydrogenase [13 (18.6\%) vs $8(11.1 \%)]$; $p$-value $<0.155$ and ferritin [4 (5.8\%) vs $4(6.3 \%)], p$-value 0.761 , were not significantly different.

The mean white blood cell count on admission was significantly higher in pregnant women than in nonpregnant women $\left(8.8 \pm 3.6\right.$ vs. $5.8 \pm 2.0 ;\left[\mathrm{x} 10^{\wedge} 3 / \mathrm{uL}\right] ; p$ $<0.01$ ); while, the platelet values were not significantly different in pregnant women at peak illness than in nonpregnant women $\left(122,000\right.$ vs. $\left.149,00010^{\wedge} 3 / \mathrm{uL}\right)$; with a $p=0.21$. There was also no significant difference between groups in liver enzymes. The Partial thromboplastin time (PTT) levels were raised in both groups at illness peak and until discharge. Haemoglobin levels were lower in pregnant women than in non-pregnant women throughout the course of the disease (peak Hb 10.2 vs. 11.2; $p<$ 0.01 ), as is expected in pregnancy. The nadir haemoglobin level was $8.5 \mathrm{~g} / \mathrm{dL}$ in pregnant women, which was similar to that of non-pregnant women $(8.9 \mathrm{~g} / \mathrm{dL})$.

\section{Severity of Covid-19 infection}

Ten $(13 \%)$ of the seventy-nine pregnant women had severe or critical Covid-19 infection that required ICU admission (Table 5). Eight of these women were in their third trimester, one was in the first trimester, and one was in the second trimester. Their mean age was 32 years. Five were overweight (BMI 25-30), while five were obese $(\mathrm{BMI} \geq 30)$. Two were diabetic and one had gestational diabetes. Two suffered from hypothyroidism. Four of these pregnant women (5\%) required non-invasive oxygen support, while six $(8 \%)$ required mechanical ventilation. One pregnant woman died of Covid-19 pneumonia due to acute respiratory distress syndrome (ARDS), multi
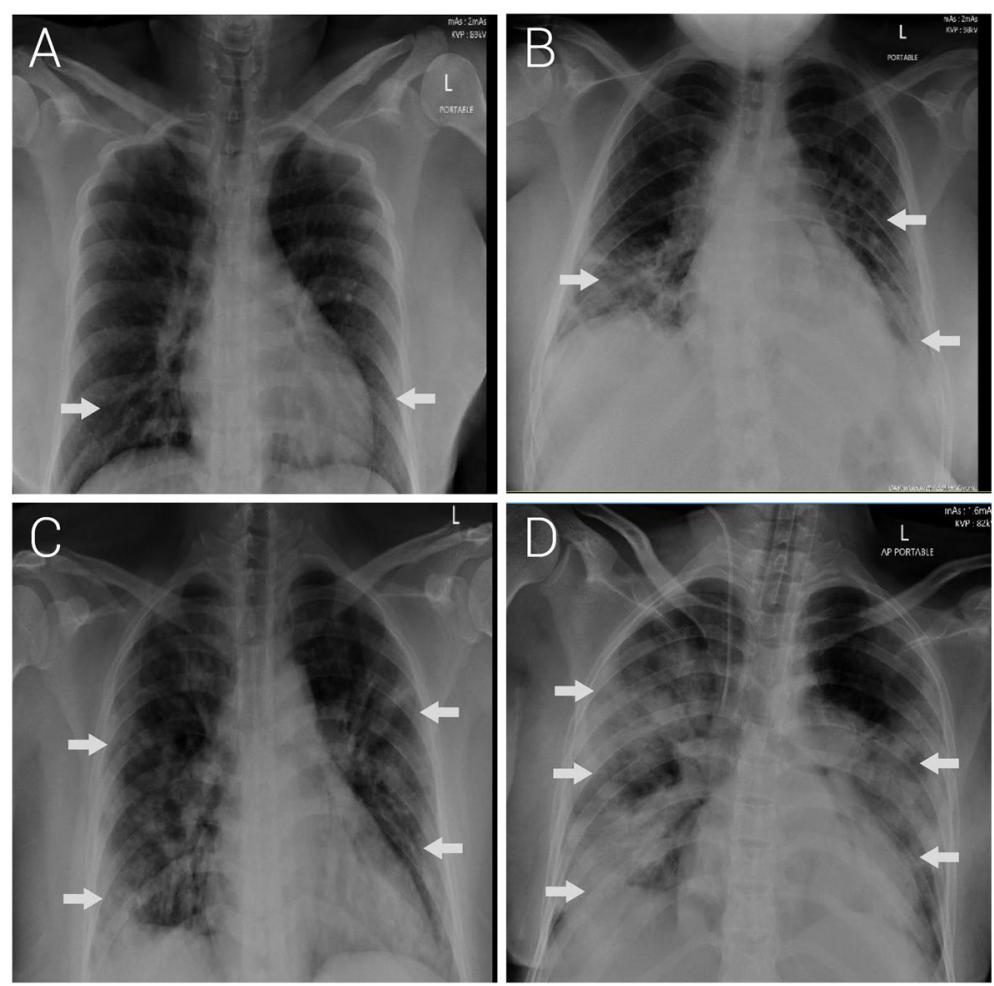

Fig. 1 Anteroposterior radiographs depicting Covid-19 pneumonia images of pregnant women with confirmed SARS-CoV-2 infection. Images were obtained at Latifa Women and Children Hospital, Dubai, from March to June 2020. A Bilateral ground glass opacities involving two lung zones with associated linear opacities seen in the periphery of the right lower zone. B III-defined patchy ground glass opacities over three lung zones. $\mathbf{C}$ Bilateral multifocal peripheral lung ground glass opacity and consolidation involving four lung zones. D Bilateral peripheral dense consolidation with loss of lung markings in five lung zones 
Table 4 Laboratory results of investigations of pregnant and non-pregnant women with confirmed SARS-CoV-2 infection

\begin{tabular}{|c|c|c|c|c|c|c|c|}
\hline Pregnant & & & & Non-pregnant & & & \\
\hline Number tested/Total $[\geq$ or & cut-off value] ( & & & Number tested/Total [ $\geq$ or & cut-off value] ( & & \\
\hline Reference range ${ }^{* *}$ & On admission & Peak & On discharge & Reference range ${ }^{* *}$ & On admission & Peak & On discharge \\
\hline $\mathrm{Hb}(<11 \mathrm{~g} / \mathrm{dl})$ & $48 / 75(64)$ & 14/43 (33) & $22 / 46(48)$ & $\mathrm{Hb}(<12 \mathrm{~g} / \mathrm{dl})$ & $57 / 84(68)$ & $11 / 23(48)$ & $13 / 24(54)$ \\
\hline WBC $(>16 \times 10 \wedge 3 / \mathrm{uL})$ & 3/74 (4) & $5 / 45(11)$ & 0/46 (28) & $\mathrm{WBC}(>11 \times 10 \wedge 3 / \mathrm{uL})$ & $1 / 84(1)$ & $2 / 23(9)$ & $1 / 24(4)$ \\
\hline $\begin{array}{l}\text { Lymphocyte }(<1.0 \times 10 \wedge 3 / \\
\text { uL) }\end{array}$ & $15 / 75(20)$ & $14 / 38(37)$ & $4 / 41(10)$ & $\begin{array}{l}\text { Lymphocyte }(<0.8 \times 10 \wedge 3 / \\
\mathrm{uL})\end{array}$ & $12 / 81(15)$ & 6/18 (33) & $3 / 18(17)$ \\
\hline $\operatorname{PLT}(<150 \times 10 \wedge 3 / \mathrm{uL})$ & $9 / 75(12)$ & 8/44 (18) & $8 / 47(17)$ & $\operatorname{PLT}(<150 \times 10 \wedge 3 / \mathrm{uL})$ & 4/83 (5) & $2 / 23(9)$ & $4 / 24(17)$ \\
\hline $\operatorname{PLT}(>400 \times 10 \wedge 3 / \mathrm{uL})$ & 2/75 (3) & $1 / 75(2)$ & 0/47 (0) & $\operatorname{PLT}(>400 \times 10 \wedge 3 / \mathrm{uL})$ & $1 / 83(1)$ & $1 / 23(4)$ & $0 / 24(0)$ \\
\hline $\mathrm{CRP}(>7 \mathrm{mg} / \mathrm{L})$ & $28 / 73(38)^{* *}$ & $15 / 22(68)$ & $14 / 34(41)$ & $\mathrm{CRP}(>7 \mathrm{mg} / \mathrm{L})$ & 13/78 (16) & $8 / 16(50)$ & $4 / 24(17)$ \\
\hline PT (>14 seconds) & $4 / 45(9)$ & 2/19 (11) & $0 / 14(0)$ & PT (>14 seconds) & 4/72 (6) & $1 / 7(14.3)$ & $0 / 7(0)$ \\
\hline PTT (>38 seconds) & $17 / 51(33)^{* *}$ & $9 / 16(56)$ & $6 / 13(46)$ & PTT (>38 seconds) & $42 / 72(58)$ & $6 / 7(86)$ & $5 / 7(71)$ \\
\hline Bilirubin (>1.2 mg/dL) & 2/65 (3) & $3(14)$ & $3 / 21(14)$ & Bilirubin (>1.2 mg/dL) & $1 / 80(1)$ & $0 / 14(0)$ & $1 / 16(6)$ \\
\hline SGPT (>40 iu/L) & $5 / 65(8)$ & $11 / 25(44)$ & $7 / 28(25)$ & $\mathrm{SGPT}(>40 \mathrm{iu} / \mathrm{L})$ & 4/81 (5) & $7 / 16(44)$ & $5 / 17(29)$ \\
\hline SGOT (>40 iu/ L) & 4/44 (9)) & $516(31)$ & $4 / 16(25)$ & $\mathrm{SGOT}(>40 \mathrm{iu} / \mathrm{L})$ & $1 / 32(3)$ & $3 / 4(75)$ & $1 / 5(20)$ \\
\hline $\mathrm{LDH}(>524 \mathrm{U} / \mathrm{L})$ & 13/70 (19) & $16 / 30(53)$ & $10 / 29(35)$ & LDH (>222 U/L) & $8 / 72(11)$ & $8 / 16(50)$ & $1 / 13(8)$ \\
\hline $\mathrm{PCT},(>0.05 \mathrm{ng} / \mathrm{ml})$ & $30 / 64(47)^{*}$ & $20 / 24(83)$ & $14 / 23(61)$ & $\mathrm{PCT},(>0.05 \mathrm{ng} / \mathrm{ml})$ & $19 / 69(28)$ & $7 / 12(58)$ & $6 / 13(46)$ \\
\hline Ferritin (>116 ng/ml) & $4 / 69(6)$ & $8 / 31(26)$ & $6 / 32(19)$ & Ferritin (>150 ng/ml) & $4 / 64(6)$ & $2 / 12(17)$ & $3 / 13(8)$ \\
\hline D-Dimer (>0.5 mcg/ml FEU) & $32 / 63(51)^{* *}$ & $15 / 26(58)$ & $9 / 29(31)$ & D-Dimer (>0.5 mcg/ml FEU) & $3 / 50(6)$ & $3 / 11(27)$ & $1 / 10(10)$ \\
\hline
\end{tabular}

Data were acquired at Latifa Hospital, Dubai, from March to June 2020

Hb Haemoglobin, WBC White blood count, PLT Platelet Count, CRP C-Reactive Protein, PT Prothrombin Time, PTT Partial Thromboplastin Time, SGPT Serum GlutamicPyruvic Transaminase, SGOT Serum Glutamic-Oxaloacetic Transaminase, LDH Lactate Dehydrogenase, $P C T$ Procalcitonin

${ }^{*} p<0.05 ;{ }^{* *} p<0.01$

** Separate reference ranged were used for pregnant women due to physiological changes during pregnancy

Table 5 Severity of the disease in pregnant and non-pregnant women with confirmed SARS-CoV-2 infection

\begin{tabular}{llll}
\hline & $\begin{array}{l}\text { Cases }(\boldsymbol{n}=\mathbf{7 9}) \\
\text { Number (\%) }\end{array}$ & $\begin{array}{l}\text { Control }(\boldsymbol{n}=\mathbf{8 5}) \\
\text { Number (\%) }\end{array}$ & $\boldsymbol{p}$-value \\
\hline Asymptomatic & $26(32)$ & $11(13)$ & 0.0035 \\
Mild & $35(44)$ & $57(67)$ & 0.0030 \\
Moderate & $8(10)$ & $13(14)$ & 0.4335 \\
Severe & $4(5)$ & $2(2)$ & 0.2940 \\
Critical & $6(8)$ & $2(2)$ & 0.0759 \\
Intubated and ventilated & $6(8)$ & $1(1)$ & 0.0290 \\
O2 support/Non- & $12(15)$ & $3(4)$ & 0.0157 \\
invasive & & & \\
Complications & $9(11)$ & $2(2)$ & 0.0184 \\
Recovery time (Mean & $16(11)$ & $15(7)$ & 0.3708 \\
(SD)) & & & 0.3569 \\
Death & $1(1)$ & 0 & \\
\hline
\end{tabular}

organ failure, septic shock and disseminated intra-vascular coagulation. The remaining 69 pregnant women were asymptomatic or had mild-to-moderate symptoms.

In the non-pregnant arm, three women required oxygen support, while only one required mechanical ventilation. All remaining 81 non-pregnant women were either asymptomatic or had mild-to-moderate symptoms. None of the non-pregnant women died. The mean recovery time for both groups ranged from 15-16 days.

\section{Treatment}

Drugs used to treat pneumonia in women with Covid-19 are shown in Table 6. Hydroxychloroquine and Lopinavir/Ritonavir were used as first-line drugs in pregnant women, because Favipiravir is contraindicated during pregnancy. Favipiravir was used in 22 (26\%) non-pregnant women. Hydroxychloroquine was used more frequently $(n=38)$ than chloroquine $(n=3)$ in pregnant women, and significantly more non-pregnant women $(n$ $=16)$ were treated with chloroquine $(p=0.002)$. Lowmolecular-weight heparin (LMWH) was used in 64 (81\%) pregnant women as compared to $30(35 \%)$ nonpregnant women $(p<0.001)$. Broad spectrum antibiotics were prescribed to 30 (38\%) pregnant women for secondary infection, compared to only $11(13 \%)$ nonpregnant women. Therapeutic LMWH was offered to 8 pregnant and 9 non-pregnant women, and prophylactic LMWH was offered to 59 pregnant and 25 non-pregnant women. Three patients received pegylated interferon, and one received Tocilizumab. Extracorporeal membrane 
Table 6 Drug treatment and outcomes of the disease, in pregnant and non-pregnant women with confirmed SARS-CoV-2 infection

\begin{tabular}{llll}
\hline & $\begin{array}{l}\text { Pregnant } \\
\text { women }(\boldsymbol{n}= \\
\text { 79) } \\
\text { No. (\%) }\end{array}$ & $\begin{array}{l}\text { Non-pregnant } \\
\text { women }(\boldsymbol{n}=\mathbf{8 5})\end{array}$ & $\begin{array}{l}\boldsymbol{P} \text {-value } \\
\text { No. (\%) }\end{array}$ \\
\hline Fydroxychloroquine & $38(48)$ & $44(52)$ & 0.377 \\
$\quad$ Lavipiravir & 0 & $22(26)$ & $<0.001$ \\
Azithromycin & $11(14)$ & $8(10)$ & 0.492 \\
Chloroquine & $3(4)$ & $16(19)$ & 0.255 \\
LMWH & $64(81)$ & $30(35)$ & 0.002 \\
Methylprednisolone & $12(15)$ & $7(8)$ & $<0.001$ \\
Interferon & $3(4)$ & 0 & 0.126 \\
Acetylcysteine & $5(6)$ & $4(5)$ & 0.110 \\
Antibiotics & $30(30)$ & $11(13)$ & 0.454 \\
Vitamin C/Nitamin D & $68(86)$ & $79(93)$ & $<0.001$ \\
O2 support/ventilated & $10(13)$ & $4(5)$ & 0.118 \\
Complication & $9(11)$ & $2(2)$ & 0.061 \\
Recovery time & & & 0.124 \\
Mean (SD) & $16(11)$ & $15(7)$ & 0.453 \\
Death & $1(1)$ & 0 & \\
\hline
\end{tabular}

oxygenation and plasma exchange were used in only one patient, who did not survive.

\section{Maternal and neonatal outcomes}

The maternal and neonatal outcomes are presented in Table 7. Thirty-one pregnant women with Covid-19 infection had a mean gestational age of 36 weeks and delivered, while infected with Covid-19, between March and June 2020. In total, 12 women had preterm, while 19 had full term deliveries. Nine of the 31 pregnant women went into spontaneous vaginal delivery (SVD), while 22 had lower segment Caesarean section (LSCS). Of the 9 who had SVD, 2 were preterm and the remaining 7 were full term.

Of the 22 women who had LSCS; 10 were preterm while 12 were full term. Thirteen out of those 22 , had emergency LSCS; 6 for Covid-19 pneumonia and 7 for obstetric reasons, including 2 for severe pre-eclampsia. Of the 6 emergency LSCS performed due to severe Covid-19 pneumonia, only 2 received betamethasone for foetal lung maturity.

The most frequent Covid-19 complications observed during hospital stay and on discharge in the 79 pregnant women were, sepsis $(n=3)$, acute renal failure $(n$ $=3)$ and ARDS $(n=5)$. One woman had post-partum haemorrhage after LSCS. Six critically ill pregnant women were in their third trimester; of these, 5 women
Table 7 Maternal and neonatal outcomes of 31 pregnant women who delivered while infected with confirmed SARSCoV-2

\begin{tabular}{|c|c|}
\hline \multicolumn{2}{|l|}{ Maternal outcome } \\
\hline Total deliveries & 31 \\
\hline Gestational age at presentation (weeks), Mean (SD) & $26(11 \%)$ \\
\hline Twin pregnancy & 2 \\
\hline Preterm deliveries & $12(38 \%)$ \\
\hline Spontaneous labour and normal delivery & $9(29 \%)$ \\
\hline Elective LSCS & $9(29 \%)$ \\
\hline Emergency LSCS & $13(42 \%)$ \\
\hline Total neonates & 31 \\
\hline LSCS for obstetric reasons & 16 \\
\hline LSCS for Covid-19 pneumonia & 6 \\
\hline Spontaneous first-trimester miscarriages & 4 \\
\hline Ruptured ectopic pregnancy & 2 \\
\hline \multicolumn{2}{|l|}{ Neonatal outcome } \\
\hline Birth weight (kg), mean (SD) & $2.8( \pm 0.7)$ \\
\hline Apgar 1 min mean (SD) & 8 \\
\hline Apgar 5 min & 9 \\
\hline Covid-19-positive & 2 \\
\hline Covid-19-negative & 29 \\
\hline Twin delivery & 1 \\
\hline Intra uterine foetal death & 1 \\
\hline Fever & 2 \\
\hline Jaundice & 12 \\
\hline \multicolumn{2}{|l|}{ Neonatal ICU admission reason } \\
\hline Jaundice & 6 \\
\hline Respiratory distress & 2 \\
\hline Prematurity & 2 \\
\hline Mother in the ICU & 1 \\
\hline Elevated inflammatory markers & 1 \\
\hline NICU total admissions & 12 \\
\hline
\end{tabular}

developed what appeared to be a severe cytokine storm and had emergency LSCS for hypoxemic respiratory failure or foetal distress. They were intubated and ventilated throughout and after surgery. One woman had severe hypoxemic respiratory failure and was intubated and ventilated 2 days postoperatively.

One of the critically ill pregnant women died. At 32 gestational weeks, she presented with cyanosis, was diagnosed with severe cytokine storm, intubated, and taken for emergency LSCS. Postoperatively, she had severe ARDS, disseminated intra-vascular coagulation and septic shock, and could not be revived.

Of the remaining 48 pregnant women who recovered from Covid-19 infection and discharged from hospital, only 35 could be followed-up. Thirteen were lost to follow-up because they were either visitors to Dubai or delivered in other private health institutions. Of those 35 women with post-Covid-19 infection records, 1 patient 
had first trimester miscarriage, 27 had term deliveries and 7 had preterm deliveries, 1 was spontaneous for twin pregnancy. Of the 27 term deliveries, 14 were performed by LSCS: 6 had electives and 8 had emergency LSCS. The remaining 20 had normal vaginal deliveries. One pregnancy was terminated due to gastroschisis that precipitated neonatal death.

The average neonatal birth weight of the 31 neonates born during mothers Covid-19 infection, was $2.8 \mathrm{~kg}$ ( \pm 0.7 ), with a mean Apgar Score at 1 minute of 8 , and at 5 minutes of 9. Two neonates were positive for Covid19; both were born by vaginal delivery. The first neonate was negative at birth, tested positive at 36 hours, and was negative on day 3 . The second neonate was negative at birth, tested positive at 24 hours, and was negative on day 2 . Both neonates remained asymptomatic throughout.

\section{Summary of results}

On admission, most pregnant women $(69 / 79 ; 87 \%)$ were either asymptomatic or suffered mild respiratory symptoms. The main symptoms, observed were fever, cough, headache, runny nose, and myalgia. In early pregnancy four women had spontaneous miscarriages and 2 had ectopic pregnancies. However, severe Covid-19 illness, ICU admission, intubation and complications were observed in late pregnancy in 10/79 (13\%) women with prior comorbidities. During the study period, 31/79 women delivered: 22 (70\%) had a lower segment Caesarean section, 16 for obstetric reasons and 6 for severe Covid-19 pneumonia; and 12 had a preterm delivery. Postoperatively, none showed significant improvement on account of early delivery. Sepsis, acute renal failure, and ARDS were the most common complications observed.

The neonatal outcome was comparable to that of the general obstetric population, even though 12/31 (38\%) were preterm and had to be admitted to the neonatal ICU. Two neonates, born by vaginal delivery, tested positive for Covid-19 after delivery. Both were asymptomatic and tests were negative within 72 hours. It was not possible to ascertain whether vertical transmission occurred in utero.

\section{Discussion}

During the first wave of the Covid-19 pandemic in the UAE, from March to June 2020, Latifa Hospital received 444 Covid-19-positive patients, including 79 pregnant women. Sero-positivity revealed a Covid-19 prevalence of $18 \%$. In this case-control study, we compared this group of women with a group of non-pregnant Covid19-positive women. Most of the pregnant women were UAE nationals or expatriates of Asian ethnic origin. Two thirds were in their third trimester of pregnancy. A third had comorbidities, such as obesity, diabetes mellitus and hypertension. The prevalence of Covid-19 infection and comorbidities were similar to those reported in China [21, 22], the UK [12], the US [14] and in systematic reviews using global data [15, 23-25].

On admission, pregnant women suffered mild respiratory symptoms, whereas non-pregnant women were more symptomatic. In both groups, the main symptoms were fever, cough, headache, runny nose and myalgia. However, 10/79 (13\%) pregnant women, including 8 in their third trimester, had a severe or critical Covid19 infection that required ICU admission. Four women required non-invasive oxygen support, while six required mechanical ventilation. In contrast, only $4 / 85$ (5\%) nonpregnant women had severe illness, with only 1 woman requiring mechanical ventilation. Our findings thus indicate that Covid-19 is more severe in late pregnancy in women with comorbidities; this supports previous findings of more ICU admissions, intubations, preterm deliveries and complications in women in late pregnancy with comorbidities [12, 14, 22].

During the study period, 31/79 women delivered; of these, $22(70 \%)$ had LSCS - 16 for obstetric reasons and 6 for severe Covid-19 pneumonia. Twelve women had a preterm delivery. Patients were prescribed hydroxychloroquine, steroids and antibiotics according to the UAE national guidelines. In most pregnant women, prophylactic thromboprophylaxis was also used. Therapeutic LMWH was administered only in serious and critical cases. Sepsis, acute renal failure and ARDS were the most common complications observed in pregnant women.

The finding that severe Covid-19 illness common in late pregnancy, particularly in women with comorbidities, has also been observed in previous studies [15]. The six pregnant women who suffered unremitting fever, cytopenia, hyperferritinemia, increased CRP, increased D-dimer and high $\mathrm{X}$-ray scores appeared to be engulfed in a typical cytokine storm, which has been described previously in pregnant women with severe Covid-19 pneumonia $[17,18]$. All these women delivered by Caesarean section due to severe maternal hypoxemia that required mechanical ventilation. However, postoperatively, none of these women showed a significant improvement in their condition on account of early delivery. On the contrary, one woman had a rather prolonged course of assisted ventilation. There was also one postpartum maternal death in a patient who underwent a Caesarean section immediately on admission. She had a prolonged course of assisted ventilation and eventually succumbed to complications of severe ARDS and septic shock. It is unclear whether the decision to perform early LSCS without adequately controlling the cytokine storm or stabilising the patient could have contributed to her death. It is possible that 
the patient's surgical trauma aggravated the cytokine response $[17,18]$.

In the current study, the neonatal outcome was comparable to the general obstetric population, even though $12 / 31$ (38\%) were preterm and had to be admitted to the neonatal ICU. There was no incidence of severe neonatal hypoxia or neonatal death, and all babies were discharged in good condition. Two neonates born by vaginal delivery were swab-positive for Covid-19 24 hours after delivery. Both were asymptomatic and tested negative within 72 hours. It was not possible to ascertain whether vertical transmission occurred in utero, during delivery via an infected birth canal, or postpartum via respiratory droplets, skin-to-skin contact or breast feeding. We did not perform tests on blood, amniotic fluid, breast milk or placental tissue; using RT-PCR. Only one intra-uterine foetal death was recorded in the current series.

The case-control study design has offered certain strengths to this study. It confirmed evidence for an association between exposure to Covod-19 and the disease. It also looked at multiple risk factors explaining severity of the disease. Pregnant women were almost equally represented in all three trimesters of pregnancy, which facilitated a comparison of the effects of Covid-19 infection at different gestational periods. Thirty-one (40\%) patients delivered while in hospital, which allowed us to assess the pregnancy outcomes. However, our study is limited by the small number of enlisted patients. Furthermore, we could not obtain laboratory confirmation of whether patients with severe illness suffered from a cytokine storm; no blood cytokines were measured. Like others, the management of patients in our study was limited by our limited experience early on during the pandemic $[15,23,24]$. Methylprednisolone was used to treat the Covid-19 infection in few patients, since our study was completed prior to the evidence presented for a greater efficacy of dexamethasone by the RECOVERY Study [26]. Similarly, chloroquine and hydroxychloroquine were used in almost half of our patients, before evidence of their ineffective role in the treatment of Covid-19 infection was presented by the WHO [27]. Finally, we could not follow up patients to observe the long-term effects of Covid-19 on both mother and baby, as patients were admitted during the emergency of the pandemic and did not attend further clinics.

\section{Conclusions}

Pregnant women presented with fewer Covid-19 symptoms such as fever, cough, sore throat, and shortness of breath compared to non-pregnant women; but they ran a much more severe course of illness. On both admission and discharge they had worse chest radiograph scores than non-pregnant women and much higher levels of laboratory indicators of disease severity. They had more ICU admissions and suffered more complications of Covid-19 infection, such as risk for miscarriage and preterm deliveries. Pregnancy with Covid-19 infection, could, therefore, be categorised as high-risk pregnancy and requires management by an obstetric and medical multidisciplinary team.

\begin{abstract}
Abbreviations
ARDS: Acute respiratory distress syndrome; BMI: Body mass index; Covid-19: Coronavirus disease 2019; ICU: Intensive care unit; LSCS: Lower segment Caesarean section; LMWH: Low-molecular-weight heparin; RT-PCR: Reverse transcription- Polymerase Chain Reaction; SARS: Severe acute respiratory syndrome; SARS-CoV-2: Severe acute respiratory syndrome coronavirus 2; UAE: United Arab Emirates.
\end{abstract}

\section{Acknowledgments}

We wish to thank all medical, nursing, administrative and staff of Latifa Hospital, Dubai for their support in conducting research in the middle of the initial shock of the Covid-19 pandemic. We also acknowledge and thank Dubai Health Authority for the immediate approval and administrative support given to this work.

\section{Authors' contributions}

$\mathrm{KSH}$ : Organization of study, compiling dataset and share in writing manuscript. $\mathrm{KSH}, \mathrm{RA}, \mathrm{LP}, \mathrm{NK}, \mathrm{ZA}, \mathrm{HM}$, TFE, MA, KM, ABF: Patient care and data collection. $\mathrm{KSH}, \mathrm{RA}, \mathrm{HM}, \mathrm{AK}, \mathrm{RB}$ : Writing manuscript. AK: Statistics. RB: Writing MS, corresponding author. The author(s) read and approved the final manuscript.

\section{Funding}

The study did not require funding.

\section{Availability of data and materials}

The datasets generated and/or analyzed during the current study are not publicly available due as the constitute part of the confidential patients records that Dubai Health Authority will not allow investigators to disclose. Anonymized summaries in the form of database, figures and tables are available from the corresponding author on reasonable request.

\section{Declarations}

Ethics approval and consent to participate

The study was approved by Dubai Scientific Research Ethics Committee (DSREC) of Dubai Health Authority (DHA). The approval was given for a retrospective study design under reference number (DSREC-05/2020_26); dated 15 June 2020. Patients informed consent was waived by DSREC as part of the policy to garner information about the Covid-19 pandemic. Therefore, patient consent was not obtained. However, all relevant data handed over to investigators, during July-August 2020, from Latifa Women and Children Hospital Health Information System "Salama", were approved by the hospital administration and anonymized to maintain patient's privacy and confidentiality. Clinical management and treatment protocols, all laboratory methods, radiographic imaging and data obtained from "Salama" hospital information system, were carried out according to relevant DHA regulations and guidelines.

\section{Consent for publication}

No individual person's data is included in this study and therefore no consent is needed.

\section{Competing interests}

None of the authors of this documents has a conflict of interest to declare.

\section{Author details}

${ }^{1}$ Latifa Women and Children Hospital, Dubai Health Authority, Dubai, United Arab Emirates. ${ }^{2}$ Rashid Hospital, Dubai Health Authority, Dubai, United Arab Emirates. ${ }^{3}$ Mohammed Bin Rashid University of Medicine and Health Sciences, 
Dubai, United Arab Emirates. ${ }^{4}$ College of Medicine, Mohammed Bin Rashid University of Medicine and Health Sciences, Dubai, United Arab Emirates.

Received: 17 January 2021 Accepted: 15 September 2021

Published online: 28 September 2021

\section{References}

1. World Health Organization. https://www.who.int/news/item/27-04-2020who-timeline\%2D\%2D-covid-19. Accessed 7 Jan 2021.

2. World Health Organization Covid-19 Dashboard. https://covid19.who.int/. Accessed 7 Jan 2021.

3. Zhu N, Zhang D, Wang W, Li X, Yang B, Song J, et al. A novel coronavirus from patients with pneumonia in China, 2019. N Engl J Med. 2020;382:727-33. https://doi.org/10.1056/NEJMoa2001017.

4. Hazari KS, Paulose L, Kurien N, Mohammad H, Elgergawi TF, Fazari AB, et al. Clinical characteristics, management, maternal and neonatal outcome among seven severe and critically ill pregnant women with COVID19 pneumonia. Clin J Obstet Gynecol. 2020;3:177-85 https://www.heigh pubs.org/cjog/cjog-aid1071.php.

5. Wong SF, Chow KM, Leung TN, Ng WF, Ng TK, Shek CC, et al. Pregnancy and perinatal outcomes of women with severe acute respiratory syndrome. Am J Obstet Gynecol. 2004;191:292-7. https://doi.org/10.1016/j. ajog.2003.11.019.

6. Jamieson DJ, Honein MA, Rasmussen SA, Williams JL, Swerdlow DL, Biggerstaff MS. Novel Influenza A (H1N1) Pregnancy Working Group et al. H1N1 2009 influenza virus infection during pregnancy in the USA. Lancet. 2009;374:451-8. https://doi.org/10.1016/S0140-6736(09)61304-0.

7. Siston AM, Rasmussen SA, Honein MA, Fry AM, Seib K, Callaghan WM, et al. Pandemic 2009 influenza A(H1N1) virus illness among pregnant women in the United States. JAMA. 2010;303:1517-25. https://doi.org/10. 1001/jama.2010.479.

8. Schwartz DA, Graham AL. Potential maternal and infant outcomes from (Wuhan) Coronavirus 2019-nCoV infecting pregnant women: lessons from SARS, MERS, and other human coronavirus infections. Viruses. 2020;12:194. https://doi.org/10.3390/v12020194.

9. Reid A. The effects of the 1918-1919 influenza pandemic on infant and child health in Derbyshire. Med Hist. 2005;49:29-54. https://doi.org/10. 1017/s0025727300008279.

10. Gottfredsson M. Spaenska veikin á Islandi 1918. Laerdómur í laeknisfraedi og sögu [The Spanish flu in Iceland 1918. Lessons in medicine and history]. Laeknabladid. 2008;94:737-45 [Icelandic.].

11. The National Perinatal Epidemiology Unit (NPEU). https://www.npeu.ox. ac.uk/ukoss/current-surveillance/covid-19-in-pregnancy. Accessed 7 Jan 2013.

12. Knight M, Bunch K, Vousden N, Morris E, Simpson N, Gale C, et al. Characteristics and outcomes of pregnant women admitted to hospital with confirmed SARS-CoV-2 infection in UK: national population-based cohort study. BMJ. 2020;369:m2107. https://doi.org/10.1136/bmj.m2107.

13. CDC National Notifiable Diseases Surveillance System (NNDSS). https:// wwwn.cdc.gov/nndss/data-and-statistics.html. Accessed 7 Jan 2013.

14. Zambrano LD, Ellington S, Strid P, Galang RR, Oduyebo T, Tong VT, et al. Update: characteristics of symptomatic women of reproductive age with laboratory-confirmed SARS-CoV-2 infection by pregnancy status United States, January 22-October 3, 2020. MMWR Morb Mortal Wkly Rep. 2020;69:1641-7. https://doi.org/10.15585/mmwr.mm6944e3.

15. Allotey J, Stallings E, Bonet M, Yap M, Chatterjee S, Kew T, et al. Clinical manifestations, risk factors, and maternal and perinatal outcomes of coronavirus disease 2019 in pregnancy: living systematic review and meta-analysis. BMJ. 2020;370:m3320. https://doi.org/10.1136/bmj.m3320.

16. NIH COVID-19 treatment guidelines. https://covid19treatmentguidelines. nih.gov/overview/management-of-covid-19/. Accessed 7 Jan 2013.

17. Hantoushzadeh S, Shamshirsaz AA, Aleyasin A, Seferovic MD, Aski SK, Arian SE, et al. Maternal death due to COVID-19. Am J Obstet Gynecol. 2020;223:109.e1-109.e16. https://doi.org/10.1016/j.ajog.2020.04.030.

18. Wang $X$, Wang $D$, He $S$. The role of a cytokine storm in severe coronavirus disease 2019 in pregnancy. Am J Obstet Gynecol. 2020;223:780-2. https://doi.org/10.1016/j.ajog.2020.07.010.

19. Toussie D, Voutsinas N, Finkelstein M, Cedillo MA, Manna S, Maron SZ, et al. Clinical and chest radiography features determine patient outcomes in young and middle-aged adults with COVID-19. Radiology. 2020;297:E197-206. https://doi.org/10.1148/radiol.2020201754.

20. National UAE Guidelines for clinical management and treatment of COVID-19. https://www.dha.gov.ae/en/HealthRegulation/Documents/ National_Guidelines_of_COVID_19_1st_June_2020.pdf. Accessed 7 Jan 2013.

21. Yan J, Guo J, Fan C, Juan J, Yu X, Li J, et al. Coronavirus disease 2019 in pregnant women: a report based on 116 cases. Am J Obstet Gynecol. 2020;223:111.e1-111.e14. https://doi.org/10.1016/j.ajog.2020.04.014.

22. Zaigham M, Andersson O. Maternal and perinatal outcomes with COVID19: a systematic review of 108 pregnancies. Acta Obstet Gynecol Scand. 2020;99:823-9. https://doi.org/10.1111/aogs.13867.

23. Juan J, Gil MM, Rong Z, Zhang Y, Yang H, Poon LC. Effect of coronavirus disease 2019 (COVID-19) on maternal, perinatal and neonatal outcome: systematic review. Ultrasound Obstet Gynecol. 2020;56:15-27. https://doi. org/10.1002/uog.22088.

24. Pettirosso E, Giles M, Cole S, Rees M. COVID-19 and pregnancy: a review of clinical characteristics, obstetric outcomes and vertical transmission. Aust NZJ Obstet Gynaecol. 2020;60(5):640-59. https://doi.org/10.1111/ ajo.13204.

25. Syeda S, Baptiste C, Breslin N, Gyamfi-Bannerman C, Miller R. The clinical course of COVID in pregnancy. Semin Perinatol. 2020;44:151284. https:// doi.org/10.1016/j.semperi.2020.151284.

26. RECOVERY Collaborative Group, Horby P, Lim WS, Emberson JR, Mafham $\mathrm{M}$, Bell JL, et al. Dexamethasone in hospitalized patients with covid-19 preliminary report. N Engl J Med. 2020. https://doi.org/10.1056/NEJMo a2021436.

27. World Health Organization. https://www.who.int/news/item/04-07-2020who-discontinues-hydroxychloroquine-and-lopinavir-ritonavir-treat ment-arms-for-covid-19. Accessed 7 Jan 2013.

\section{Publisher's Note}

Springer Nature remains neutral with regard to jurisdictional claims in published maps and institutional affiliations.

Ready to submit your research? Choose BMC and benefit from:

- fast, convenient online submission

- thorough peer review by experienced researchers in your field

- rapid publication on acceptance

- support for research data, including large and complex data types

- gold Open Access which fosters wider collaboration and increased citations

- maximum visibility for your research: over 100M website views per year

At BMC, research is always in progress.

Learn more biomedcentral.com/submissions 